Delft University of Technology

\title{
Investigation on the DC CB Performance during a Current Interruption Failure at First Current Zero
}

Liu, Siyuan; Geng, Yingsan; Popov, Marjan; Wang, Jianhua; Liu, Zhiyuan; Zhang, Bojian

DOI

10.1109/DEIV.2018.8537159

Publication date

2018

Document Version

Final published version

Published in

ISDEIV 2018 - Proceedings of the 28th International Symposium on Discharges and Electrical Insulation in Vacuum

\section{Citation (APA)}

Liu, S., Geng, Y., Popov, M., Wang, J., Liu, Z., \& Zhang, B. (2018). Investigation on the DC CB

Performance during a Current Interruption Failure at First Current Zero. In L. T. Falkingham, \& E. Kaneko

(Eds.), ISDEIV 2018 - Proceedings of the 28th International Symposium on Discharges and Electrical Insulation in Vacuum (Vol. 2, pp. 559-562). [8537159] Institute of Electrical and Electronics Engineers (IEEE). https://doi.org/10.1109/DEIV.2018.8537159

Important note

To cite this publication, please use the final published version (if applicable).

Please check the document version above.

\section{Copyright}

Other than for strictly personal use, it is not permitted to download, forward or distribute the text or part of it, without the consent of the author(s) and/or copyright holder(s), unless the work is under an open content license such as Creative Commons.

Takedown policy

Please contact us and provide details if you believe this document breaches copyrights.

We will remove access to the work immediately and investigate your claim. 
Green Open Access added to TU Delft Institutional Repository

'You share, we take care!' - Taverne project

https://www.openaccess.nl/en/you-share-we-take-care

Otherwise as indicated in the copyright section: the publisher is the copyright holder of this work and the author uses the Dutch legislation to make this work public. 


\section{Investigation on the DC CB Performance During a Current Interruption Failure at First Current Zero}

\author{
Siyuan Liu \\ State Key Laboratory of Electrical \\ Insulation and Power Equipment, \\ $X i^{\prime}$ an Jiaotong University \\ Xi'an, China \\ Liusiyuan007@stu.xjtu.edu.cn \\ Yingsan Geng \\ State Key Laboratory of Electrical \\ Insulation and Power Equipment, \\ Xi'an Jiaotong University \\ Xi'an, China \\ Ysgeng@mail.xjtu.edu.cn
}

\author{
Marjan Popov \\ Intelligent Electrical Power Grids \\ Delft University of Technology \\ Delft, Netherlands \\ M.Popov@tudelft.nl \\ Jianhua Wang \\ State Key Laboratory of Electrical \\ Insulation and Power Equipment, \\ $X i^{\prime}$ an Jiaotong University \\ Xi'an, China \\ Jhwang@xjtu.edu.cn
}

\author{
Zhiyuan Liu \\ State Key Laboratory of Electrical \\ Insulation and Power Equipment, \\ $X i^{\prime}$ an Jiaotong University \\ Xi'an, China \\ Liuzy@xjtu.edu.cn \\ Bojian Zhang \\ State Key Laboratory of Electrical \\ Insulation and Power Equipment, \\ $X i^{\prime}$ an Jiaotong University \\ Xi'an, China \\ Nemo.bojian@gmail.com
}

\begin{abstract}
The vacuum interrupter is used as the key component of an active DCCB due to its excellent interruption and dielectric recovery characteristics after current zero. The vacuum interrupter can only interrupt the fault currents below the limitation of a critical di/dt and TIV, otherwise it causes a reignition and the interruption failure. In this paper, a detailed active injection DC CB model is developed, considering operation delay of switches, parasitic parameters of switches and thorough control logic. The limitation dielectric strength between the vacuum gap is defined by the cold break down voltage. Based on the numerical modelling, investigation will be performed to see the performance of DC CB with a failure interruption on the first current zero. The simulation results can help to optimize the injection circuit parameters when DC $C B$ has a failure on the first current zero and has to interrupt in the next current zeros. This algorithm will consider predefined threshold of di/dt, chopping current and variable operation time in different scenarios.
\end{abstract}

Keywords-HVDC circuit breaker, fault interruption, di/dt, active injection, PSCAD simulation

\section{INTRODUCTION}

The insistent demands of renewable energy significantly promotes the topology of the future energy transmission systems. Significant progress has been made on the development of Voltage Source Converter (VSC) based HVDC grids in the last few years, which enable meshed HVDC grid to provide a promising technological solution for the connection of offshore wind farms [1]. The development of meshed HVDC offshore grids is hindered by a few technical barriers. One of the main barriers is the lack of reliable, fast, low loss and cost effective HVDC circuit breakers (CB), which can allow isolation of fault segments of the HVDC grid and keep the healthy areas operating continuously [2].

Due to the absence of a natural current zero in DC system, traditional AC circuit breakers cannot clear the fault that occurs in HVDC grids. An artificial current zero is generated by active injection of high frequency oscillation current. Besides the

Project Supported by National Program on Key Basic Research Project (973 Program) (2015CB251002), National Natural Science Foundation of China (51323012, 51221005). generation of current zero, the DCCB also needs to withstand the transient interruption voltage (TIV) and dissipate the magnetic energy stored in DC system. The vacuum interrupter can only interrupt the fault currents when the current slope at current zero (di/dt) below the critical limitation and TIV less than the insulation strength of vacuum interrupter.

Large numbers of researches have been done on the limitation of vacuum interruption. Mathematical modeling of the high frequency behavior of vacuum interrupters is performed in [3], and the critical di/dt is measured as 150-1000 $\mathrm{A} / \mu \mathrm{s}$ for $\mathrm{AC} \mathrm{CBs}$ at high frequency. Overvoltage and reignition behavior of vacuum interrupter are carried out in [4] by numerical modelling and the interruption is determined by the critical $\mathrm{di} / \mathrm{dt}$ and dielectric strength. However, the important failure scenarios of DC current interruption are not investigated so far.

In this paper, a detailed active injection DC CB model is developed, considering chopping current of switches, gap distance dynamic and thorough control logic. The limitation dielectric strength between the vacuum gap is defined by the cold break down voltage. Based on the numerical modelling, investigation will be performed to see the performance of DC $\mathrm{CB}$ with a failure interruption on the first current zero. The simulation results can help to optimize the injection circuit parameters when DC CB has a failure on the first current zero and has to interrupt in the next current zeros. This algorithm will consider predefined threshold of $\mathrm{di} / \mathrm{dt}$ and insulation strength in different scenarios. And the results obtained in PSCAD platform will be analyzed by equations.

\section{Modelling of the Mechanical DC CB}

\section{A. Model Structure and Parameters}

Figure 1 shows the structure of mechanical DC CB model [5], which consists of three branches, namely, the main branch, the current injection branch and energy absorption branch. Three high speed $72.5 \mathrm{kV}$ vacuum interrupters $\left(\mathrm{S}_{1 \mathrm{a}}, \mathrm{S}_{1 \mathrm{~b}}\right.$ and $\left.\mathrm{S}_{1 \mathrm{c}}\right)$ are connected in series in the main branch to withstand the 
system voltage. A residual breaker $\left(\mathrm{S}_{2}\right)$ is used to insulate the $\mathrm{CB}$ after current interruption. A switchable resonant circuit in connected in parallel with the vacuum interrupters (VIs) which is comprised of inductor $\left(\mathrm{L}_{\mathrm{p}}\right)$, capacitor $\left(\mathrm{C}_{\mathrm{p}} \mathrm{a} / \mathrm{b}\right)$ and injection switch $\left(\mathrm{S}_{3}\right)$. The surge arrester (SA) absorb the residual energy in DC grid after interruption. The one and only external trip signal $\mathrm{K}_{\text {grid }}$ is a logic signal $\left(\mathrm{K}_{\text {grid }}=1\right.$ is close; $\mathrm{K}_{\text {grid }}=0$ is open). The DC CB parameters are shown in Table 1.

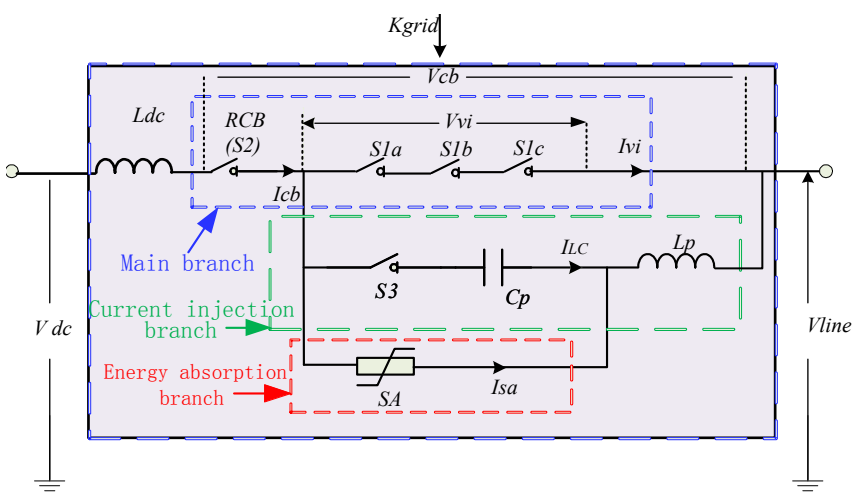

Figure 1 Structure of Mechanical DC CB

Table 1 Parameters

\begin{tabular}{|c|c|c|c|}
\hline Resonant Branch Parameters & Label & \multicolumn{2}{|c|}{ Value } \\
\hline Rated voltage & $\mathrm{V}_{\mathrm{dc}}$ & 200 & {$[\mathrm{kV}]$} \\
\hline Resonant branch inductance & $\mathrm{L}_{\mathrm{p}}$ & 400 & {$[\mu \mathrm{H}]$} \\
\hline Resonant branch capacitance & $\mathrm{C}_{\mathrm{p}}$ & 2.5 & {$[\mu \mathrm{F}]$} \\
\hline SA rated/ clamping voltage & $\mathrm{V}_{\mathrm{SA}}$ & $200 / 300$ & {$[\mathrm{kV}]$} \\
\hline VIs operation delay & $\mathrm{T}_{\mathrm{mec}}$ & 4 & {$[\mathrm{~ms}]$} \\
\hline $\mathrm{S}_{3}$ closing delay & $\mathrm{T}_{\mathrm{d} 3}$ & 4 & {$[\mathrm{~ms}]$} \\
\hline Inductance of current limiter & $\mathrm{L}_{\mathrm{dc}}$ & 75 & {$[\mathrm{mH}]$} \\
\hline
\end{tabular}

\section{B. DC CB Operation Sequence}

The detail DC CB operation sequence is obtained from [1], Figure 2 illustrates the fault current interruption process and the relevant voltages, currents and switch states. The trip order is sent $2 \mathrm{~ms}$ after the fault inception. Afterwards, the DC CB begin to operate as soon as it receives the trip signal.

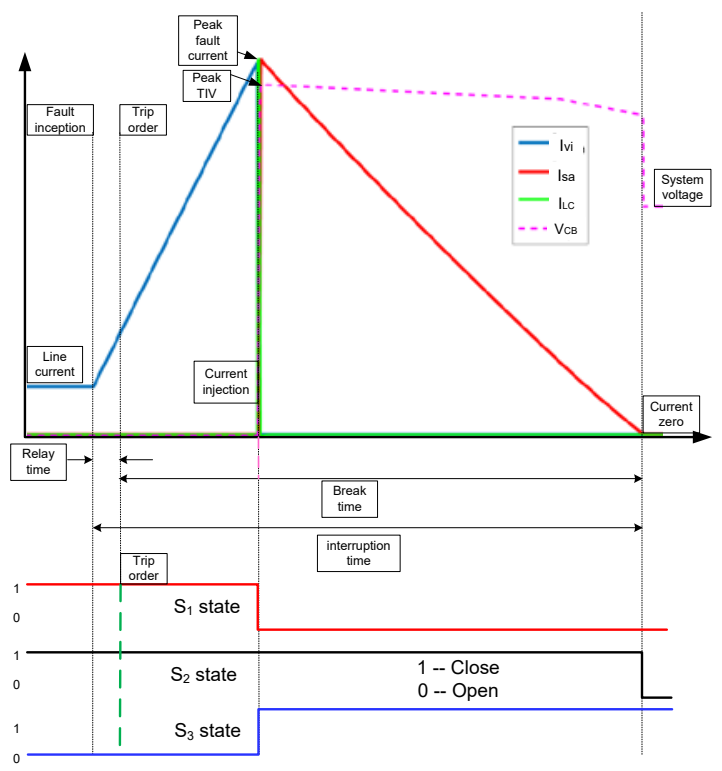

Figure 2 DC CB operation sequence

\section{Fast Operation Mechanism}

In order to promptly interrupt the fault, a fast operating mechanism is applied to the vacuum interrupter. Figure 3 shows the structure of the fast operating mechanism. The fast operating mechanism is used to drive the $72.5 \mathrm{kV}$ vacuum interrupter. The fast vacuum circuit breaker includes a vacuum interrupter, an insulation pole, a spring unit, a driving unit and an oil damper. The vacuum interrupter is used to interrupt the fault current, and the insulation pole is used to pull the moving contact during the operation. The spring unit provides the pretightening force to the vacuum interrupter contacts. Thompson coils are applied in the driving unit to separate the contact fast so that gap distance reached a sufficient distance in short period. And the driving unit provides the power for opening and closing operation. The full gap distance of one vacuum interrupter is $20 \mathrm{~mm}$.

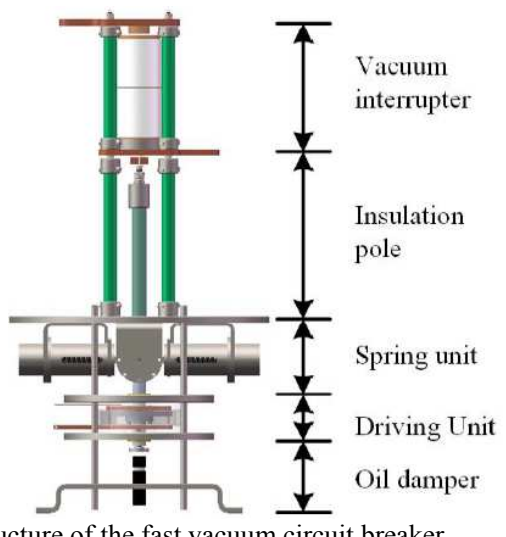

Figure 3 The structure of the fast vacuum circuit breaker

In the demonstration circuit, the fault occurs at $\mathrm{t}=0.01 \mathrm{~s}$ and the system detect the fault and the trip signal is sent to the DC $\mathrm{CB}$ with a $2 \mathrm{~ms}$ delay. The $\mathrm{DC} \mathrm{CB}$ operates as soon as it receives the trip signal. In the first millisecond of the opening operation, the fast operating mechanism overcomes the pretightening force and the gap distance remains $0 \mathrm{~mm}$ during this period. Afterwards, the contact separates very quickly and the gap distance increases sharply until the moving contact hits the damper. The moving contact rebounds when it hits the damper, and then separates slowly under the action of the opening driving force and the damping of the oil damper. Thereafter, the gap distance decreases after the rebound and then increases slowly until it reaches the full gap distance. Figure 4 shows the measured variation of the dynamic gap distance in vacuum interrupter with the time, which is measured by high speed camera.

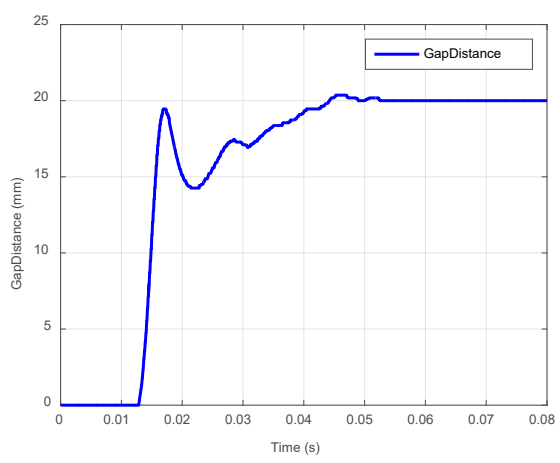

Figure 4 Dynamic gap distance 


\section{VACUUM INTERRUPTION LIMATATION}

\section{A. Insulation Strength}

For now, no commercial single break vacuum interrupters are available to withstand $200 \mathrm{kV}$, so three vacuum interrupters are connected in series to withstand the system voltage together, as shown in Figure 1. With the help of voltage sharing resistors and capacitors, it assumes that the three vacuum interrupters share the voltage equally. The insulation strength $\left(\mathrm{U}_{\mathrm{b}}\right)$ of the vacuum interrupter is a function of the gap distance (s) [7]; $f$ and $\alpha$ are parameters depending on the geometry of the coplanar profile, as (1) where $f$ is $30 \mathrm{kV} /(\mathrm{mm})^{\alpha}$ and $\alpha$ is 0.45 . As a result, the total insulation strength $\left(U_{I S}\right)$ of the DCCB is three times of the single vacuum interrupter (2), $N_{V I}$ is the number of the VIs. Then we get the equivalent equation as (3).

$$
\begin{gathered}
U_{b}(s)=f \bullet s^{\alpha} \\
U_{I S}=N_{V I} \bullet U_{b}(s) \\
U_{I S}=N_{V I} \bullet f \bullet s^{\alpha}
\end{gathered}
$$

The total insulation strength $\left(U_{I S}\right)$ of VIs versus time based on gap distance dynamic can be obtained by (3), and the results is shown in Figure 5. The vacuum interrupter will not reignite when the TIV absolute value is lower than the insulation strength, which means the contacts gap withstands the TIV after fault interruption; this state is considered as an open state (high impendence: $1 \mathrm{e}^{15} \Omega$ ). On the other hand, when the TIV absolute value exceeds the insulation strength during the interruption process, the contact gap cannot withstand the TIV and a re-ignition occurs. The vacuum interrupter switches to a close state (low impendence: $1 \mathrm{e}^{-3} \Omega$ ).

\section{B. Current Slope at current zero}

In practice, the maximum quenching capability of the $\mathrm{di} / \mathrm{dt}$ of the vacuum interrupter depends on the characteristic of the vacuum interrupter. The maximum value range according to [3], is $150-1000 \mathrm{~A} / \mathrm{us}$ and this value is influenced by many factors, such as the interruption current and the current frequency. These parameters are measured at $1.8 \mathrm{MHz}$ with a small gap distance in the order of several hundred micrometers. The CB is not capable to interrupt fault current at zero crossing if the $\mathrm{di} / \mathrm{dt}$ value is higher than the limitation. If the DCCB failed to interrupt the fault current on the first current zero, the $\mathrm{DC} C \mathrm{CB}$ still has a chance to interrupt the current in the coming current zeros, for the reason that the superimpose of oscillation current and rising fault current will generate current zero with less $\mathrm{di} / \mathrm{dt}$ Until the di/dt decreases less than the limitation, the fault current can be cleared by the vacuum interrupter. In [8]-[11], the critical of di/dt current derivative are considered as a constant. An method for determination of the quenching capability of a black-box VI model is proposed by [12], a linear equation (4) is used to define the high frequency capability

$$
d i / d t=C\left(t-t_{0}\right)+D
$$

The constant in (4) is also given in [12] and [4], where $\mathrm{C}$ and $\mathrm{D}$ is $-0.034 \mathrm{~A} / \mathrm{us}$ and $255 \mathrm{~A} / \mathrm{us}$, respectively. $\mathrm{t}_{0}$ is the contacts separating instant. The vacuum interrupter can clear the fault current at zero crossing when the di/dt is below the limitation, otherwise, the vacuum interrupter is not capable to clear the fault.

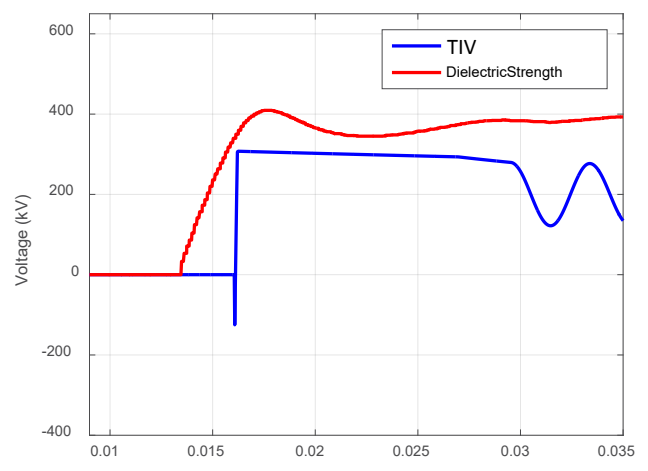

Figure 5 Corresponding insulation strength and TIV versus time

\section{SimUlation VeRIFICATIONS}

\section{A. Demonstration System}

Figure 6 shows the demonstration system, the DC CB is interfaced to a DC source and the fault occurs at $\mathrm{t}=0.01 \mathrm{~s}$. The parameters of the system are shown in Table 2. The nominal load current is $1 \mathrm{kA}$.

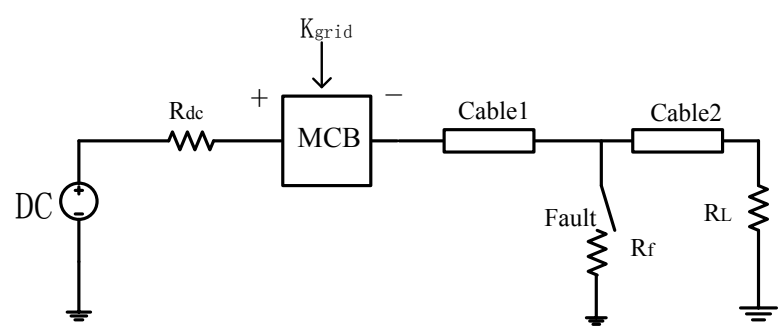

Figure 6 Demonstration system

Table 2 Demonstration system parameters

\begin{tabular}{|l|l|}
\hline \multicolumn{1}{|c|}{ Parameter } & \\
\hline $\mathrm{V}_{\mathrm{dc}}$ & $200 \mathrm{kV}$ \\
\hline $\mathrm{R}_{\mathrm{dc}}$ & $0.1 \Omega$ \\
\hline DC cable 1 & $10 \mathrm{~km}$ frequency dependent(phase) model \\
\hline DC cable 2 & $10 \mathrm{~km}$ frequency dependent(phase) model \\
\hline $\mathrm{R}_{\mathrm{f}}$ (low impedance) & $0.1 \Omega$ \\
\hline $\mathrm{R}_{\text {load }}$ (rated load) & $\begin{array}{l}200 \Omega \text { (Suggested value to give required load } \\
\text { current, but may be different depending on DC } \\
\text { CB rating) }\end{array}$ \\
\hline
\end{tabular}

\section{B. Simulation results}

Figure 7 shows the result of the TIV during a failed interruption caused by an early injection. The making switch closes at $3.5 \mathrm{~ms}$ after the trip signal is applied, which is $0.5 \mathrm{~ms}$ earlier than the supposed injection time. Therefore, the contact gap has not reached a sufficient distance to withstand the TIV. As it can be seen in the zoomed traces shown in zoom in figure, TIV begins to build up from $\mathrm{t}=15.5 \mathrm{~ms}$ until it exceeds the critical gap insulation strength. At this instant, a re-ignition occurs and the voltage across the vacuum interrupter drops 
sharply to the arc voltage (which in practice is in the order of tens of volts). The capacitor in the resonant branch is charged to approximately $280 \mathrm{kV}$ (5) during TIV build up process and the capacitor discharges through the inductor when a reignition occurs generating a higher current impulse $\left(\mathrm{I}_{\mathrm{LC}}\right)$ in $(6)$, as shown in Figure 8. The vacuum interrupter current in second half cycle is (7), the current through the vacuum interrupter $\left(\mathrm{I}_{\mathrm{VI}}\right)$ drops to zero a half cycle later. The TIV builds up again until it reaches the clamping voltage of surge arrester. The current is then commutated into the energy absorption branch $\left(\mathrm{I}_{\mathrm{sa}}\right)$.

$$
\begin{gathered}
V_{c} \approx V_{\text {Clamp }}=1.5 V_{d c} \\
I_{L C}=V_{C} \sqrt{\frac{C_{p}}{L_{p}}} \\
I_{V I}=I_{f}+I_{L C}
\end{gathered}
$$

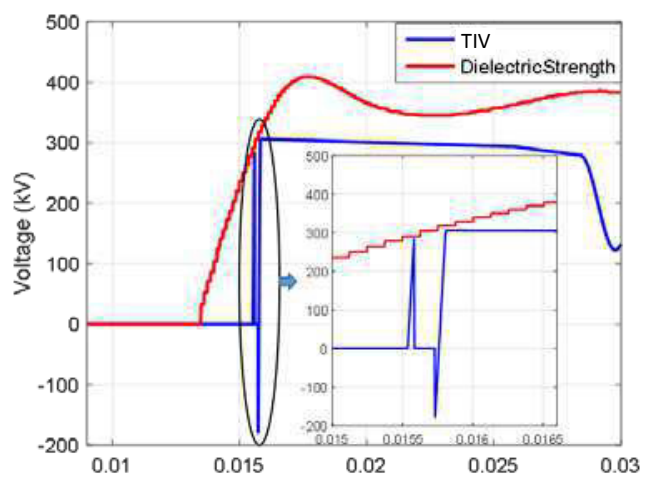

Figure 7 TIV during an interruption failure caused by early injection

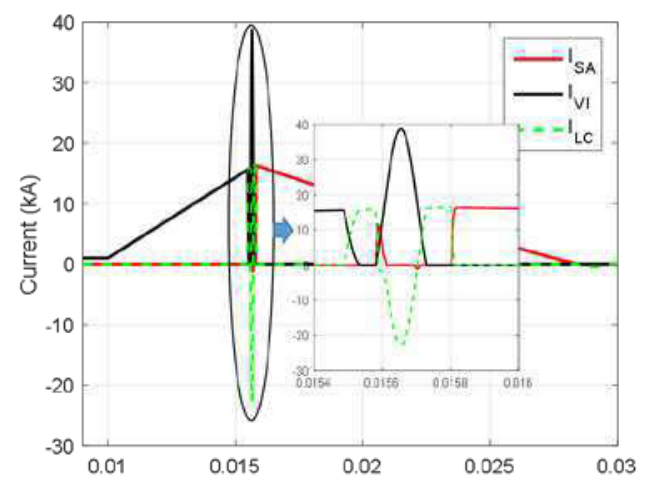

Figure 8 Currents during an interruption failure caused by early injection

\section{CONCLUSION}

A detailed active injection DC CB model is developed, considering the limitation of the insulation strength and $\mathrm{di} / \mathrm{dt}$ at current zero. The insulation strength is obtained from the dynamic gap distance measured on fast operation mechanism. Detail scenario of interruption failure as first current zero caused by early injection is demonstrated. The results show the DC $\mathrm{CB}$ performance with an interruption failure at the first current zero. The DC CB can still interrupt the fault in the next current zeros, for the reason that the superimposed oscillation current and the rising fault current will generate a current zero with a lower di/dt. Until the di/dt and TIV decreases below the critical values, the fault current can be cleared by the vacuum interrupter. During the process of re-ignition, it can be seen that the voltage spikes progressively increase with the increase of the withstand capability. The higher value of TIV has also impact on the amplitude of the reignited current. Furthermore, the contact distance defines the amplitude of the withstand voltage. This implies that when a re-ignition takes place, the level of the TIV will depend on the contact distance at which the TIV exceeds the insulation strength. Analogously, higher system voltage will also results in higher current spike

\section{ACKNOWLEDGMENT}

The authors would like to appreciate Prof. Rene Smeets, for his helpful suggestion and valuable comment to the vacuum interruption modelling part.

\section{REFERENCES}

[1] S. Liu, M. Popov, "Development of HVDC System-level Mechanical Circuit Breaker Model" International Journal of Electrical Power \& Energy Systems Volume 103, December 2018, Pages 159-167

[2] N. A. Belda, C. Plet, and R. P. P. Smeets, "Analysis of Faults in Multi Terminal HVDC Grid for Definition of Test Requirements of HVDC Circuit Breakers," IEEE Transactions on Power Delivery, vol. PP, no. 99 , pp. 1-1, 2017.

[3] Helmer J, Lindmayer M. "Mathematical modeling of the high frequency behavior of vacuum interrupters and comparison with measured transients in power systems" //Discharges and Electrical Insulation in Vacuum, 1996. Proceedings. ISDEIV., XVIIth International Symposium on. IEEE, 1996, 1: 323-331.

[4] Wong S M, Snider L A, Lo E W C. "Overvoltages and reignition behavior of vacuum circuit breaker". Proceedings of the 6th Intrrnatianal Conference on Advances in Power System Control, Oprrauon and hlanagement, APSCOM, 2003.

[5] K. Tahata et al., "Investigation of suppression effect of short-circuit current and voltage drop in multi-terminal HVDC by DC reactor," in 2015 3rd International Conference on Electric Power Equipment \&\#8211; Switching Technology (ICEPE-ST), 2015, pp. 240-245.

[6] Zhang B, Wang J. A Relationship between Minimum Arcing Interrupting Capability and Opening Velocity of Vacuum Interrupters in Short-circuit Current Interruption. IEEE Transactions on Power Delivery, 2018 .

[7] Schumann U, Giere S, Kurrat M. "Breakdown voltage of electrode arrangements in vacuum circuit breakers". IEEE transactions on dielectrics and electrical insulation, 2003, 10(4): 557-562.

[8] J. Panek and K. G. Fehrle, "Overvoltage phenomena associated withvirtual current chopping in three phase circuits," IEEE Trans Power App. Syst., vol. PAS-94, no. 4, pt. 1, pp. 1317-1325, Jul. 1975.

[9] L. Czarnecki and M. Lindmayer, "Measurement and statistical simulation of multiple reignitions in vacuum switches," IEEE Trans. Plasma Sci. , vol. PS-13, no. 5, pp. 304-310, Oct. 1985.

[10] J. Kosmac and P. Zunko, "Statistical vacuum circuit breaker model for simulation of transient overvoltages," IEEE Trans. Power Del., vol. 10, no. 1, pp. 294-300, Jan. 1995.

[11] A. M. Chaly and A. T. Chalaya, "Computer simulation of transformermagnetising current interruption by a vacuum circuit breaker," in Proc.Int. Symp. Discharges Elect. Insul. Vacuum, 1996, vol. 1, pp. 249-253.

[12] M. T. Glinkowski, M. R. Gutierrez, and D. Braun, "Voltage escalation and reignition behavior of vacuum generator circuit breakers during load shedding," IEEE Trans. Power Del., vol. 12, no. 1, pp. 219-226, Jan. 1997.

E-mail of the author(s): Liusiyuan007@stu.xjtu.edu.cn 